\title{
Increment of plasma glucose by exogenous glucagon is associated with present and future renal function in type 2 diabetes:a retrospective study from glucagon stimulation test
}

\author{
Yasutaka Takeda ${ }^{1}$, Yukihiro Fujita ${ }^{1,2^{*}}$ (D), Ryoichi Bessho ${ }^{1}$, Mao Sato ${ }^{1}$, Tomoe Abe ${ }^{1}$, Tsuyoshi Yanagimachi ${ }^{1,2}$,
} Hidemitsu Sakagami ', Atsuko Abiko', Yumi Takiyama', Tsuguhito Ota ${ }^{1}$ and Masakazu Haneda'

\begin{abstract}
Background: Glucagon stimulation test (GST) is often employed to assess the insulin reserve of the pancreatic beta cells in diabetic subjects. The clinical significance of the increment of plasma glucose ( $\Delta$ glucose) by exogenous glucagon during GST has not been elucidated. We investigated the relationship between $\Delta$ glucose and clinical parameters including the liver and renal function in type 2 diabetic subjects, since we hypothesized that $\Delta$ glucose is associated with the liver and renal function reflecting the capacity for gluconeogenesis in the organs.

Methods: A total of 209 subjects with type 2 diabetes who underwent GST during admission were included in this cross-sectional study. We defined the difference between plasma glucose at fasting and $6 \mathrm{~min}$ after intravenous injection of $1 \mathrm{mg}$ glucagon as $\Delta$ glucose. We assessed correlations between $\Delta$ glucose and clinical parameters such as diabetic duration, BMI, HbA1c, beta cell function, serum free fatty acids (FFA) which is known to stimulate gluconeogenesis, liver function, the indices of liver function, renal function, and urinary albumin excretion (UAE).

Results: In correlation analysis, $\Delta$ glucose positively correlated to FFA and estimated glomerular filtration rate (eGFR), but inversely to serum creatinine and cystatin $C$, although $\Delta$ glucose showed no correlation with both liver function and the indices of residual liver function. Multiple regression analysis revealed that $\Delta$ glucose was an independent determinant for the eGFR after 1 year, equally BMI, HbA1c, serum lipids, and UAE, which are known as the predictors for the development of chronic kidney disease.
\end{abstract}

Conclusion: Our results suggest that $\Delta$ glucose during GST might be related to gluconeogenesis in the kidney and could be the determinant of future renal function in type 2 diabetes.

Keywords: Glucagon, $\Delta$ Glucose, Free fatty acid, Renal function, Gluconeogenesis

\footnotetext{
* Correspondence: yfujita@asahikawa-med.ac.jp

${ }^{1}$ Division of Metabolism and Biosystemic Science, Department of Internal

Medicine, Asahikawa Medical University, 2-1-1-1 Midorigaoka Higashi,

Asahikawa 078-8510, Japan

${ }^{2}$ Division of Diabetology, Endocrinology and Nephrology, Department of

Internal Medicine, Shiga University of Medical Science, Otsu, Japan
}

(c) The Author(s). 2019 Open Access This article is distributed under the terms of the Creative Commons Attribution 4.0 International License (http://creativecommons.org/licenses/by/4.0/), which permits unrestricted use, distribution, and

reproduction in any medium, provided you give appropriate credit to the original author(s) and the source, provide a link to the Creative Commons license, and indicate if changes were made. The Creative Commons Public Domain Dedication waiver (http://creativecommons.org/publicdomain/zero/1.0/) applies to the data made available in this article, unless otherwise stated. 


\section{Background}

Glucagon, secreted from pancreatic alpha cells, promotes hepatic glucose output (HGO) by stimulating both gluconeogenesis and glycogenolysis in the liver to maintain blood glucose levels and also stimulates insulin secretion from islet beta cells in glucose-independent manner in humans [1]. Glucagon stimulation test (GST) has been often used to assess the insulin reserve of the pancreatic beta cells in subjects with diabetes by measuring plasma C-peptide immunoreactivity (CPR) levels before and 6 min after exogenous intravenous glucagon injection $[2,3]$. Although the increment of plasma glucose levels ( $\Delta$ glucose) by exogenous glucagon during GST is presumed to reflect a part of glucose output from the liver that might be attributed to gluconeogenesis and glycogenolysis, the clinical significance of $\Delta$ glucose has not been elucidated.

The kidney also plays crucial roles in glucose metabolism via gluconeogenesis, glucose utilization, glucose reabsorption and glucose disposal from the renal glomerular filtrate. After an overnight fast, $50 \%$ of the glucose release into the circulation is the result of glycogenolysis in the liver and the other half is due to gluconeogenesis from lactate, glycerol, alanine and other amino acids both in liver and kidney [4]. Focusing on the gluconeogenesis, the kidney provides almost equal amounts of glucose to the liver into the circulation in the postabsorptive state [4].

In addition to insulin resistance in the liver, hyperglucagonemia in both fasting and postprandial states leads to increased rates of $\mathrm{HGO}$, a major factor in the elevation of the blood glucose levels in type 2 diabetes mellitus (T2DM) [1]. On the other hand, Meyer and colleagues unveiled that renal glucose release as a result of gluconeogenesis into the circulation is increased in subjects with T2DM and its increment is comparable to the liver [5]. Consequently, glucose overproduction probably resulting from increased gluconeogenesis from both the liver and the kidney is closely involved in hyperglycemia in T2DM.

Indeed, gluconeogenesis can be modified in pathophysiological condition in the liver and the kidney. In 1970s, Frizzell and colleagues reported that spontaneous hypoglycemia in patients with renal failure occurred in association with decreased renal glucose production [6]. Furthermore, Garber et al. showed that an inadequate delivery of alanine, that is an important gluconeogenic substrate in the kidney, can cause fasting hypoglycemia in renal failure [7]. On the other hand, a recent study using magnetic resonance spectroscopy revealed that gluconeogenesis in patients with severe cirrhosis was decreased [8]. Interestingly, Joseph and colleagues revealed that extrahepatic tissues, especially the kidney, make a significant contribution to increased endogenous glucose production by gluconeogenesis in cases during anhepatic phase of liver transplantation without glucose production from the liver [9]. Thus, the liver and the kidney functions are thought to be related to gluconeogenesis in each organ.

Consequently, we hypothesized that $\Delta$ glucose by exogenous glucagon during GST can reflect gluconeogenesis in not only the liver but also the kidney, and associate with the liver and renal function in T2DM. To validate this hypothesis, we investigated the relationship in subjects with T2DM between $\Delta$ glucose and clinical parameters such as aspartate aminotransferase (AST) and alanine aminotransferase (ALT) as liver function, serum creatinine, cystatin $\mathrm{C}$ and estimated glomerular filtration rate (eGFR) as renal function, serum free fatty acids (FFA) which is known to stimulate gluconeogenesis, and albumin, cholinesterase (ChE), bilirubin, total cholesterol, triglyceride, high-density lipoprotein (HDL) cholesterol, low-density lipoprotein (LDL) cholesterol, and prothrombin time (PT) employed as the indices reflecting residual liver function.

\section{Methods \\ Participants}

We included a total of 209 (108 male and 101 female) Japanese patients with T2DM who underwent GST during admission in Asahikawa Medical University Hospital from 2013 to 2016, in this cross-sectional study. There was no participant who had symptomatic cerebrovascular disorders, severe heart disease, hepatitis and liver cirrhosis, renal failure (exclusion criteria: eGFR below $30 \mathrm{ml} \mathrm{min}^{-1} 1.73 \mathrm{~m}^{-2}$ or serum creatinine above $2.0 \mathrm{mg} / \mathrm{dl}$ ), and malignant neoplasm, who was in the pre- or post-operative period, or who was positive for diabetes-related autoantibodies. The protocol of the current study was approved by the ethics committee of Asahikawa Medical University (Approval number: 17104).

\section{Study protocol and measurement}

Prior to GST, all inpatient participants were treated with appropriate diet and insulin-based glucose lowering treatments after administration, resulting in fasting glucose levels and pre-meal glucose levels of $140 \mathrm{mg} / \mathrm{dl}$ or less to avoid glucotoxicity. No subjects received rapid-acting insulin after $6 \mathrm{pm}$ on the 1 day before GST. Some participants received long acting insulin such as insulin glargine, insulin detemir or insulin degludec subcutaneously at $8 \mathrm{pm}$ the day before GST to maintain adequate fasting blood glucose levels. Then, GST was carried out at 8 am after an overnight fast by measuring serum CPR at fasting and $6 \mathrm{~min}$ after single intravenous injection of $1 \mathrm{mg}$ glucagon (Novo Nordisk, Tokyo, Japan). We defined the increment of serum CPR after glucagon injection as $\triangle \mathrm{CPR}$, the difference between plasma glucose at fasting and $6 \mathrm{~min}$ after glucagon 
injection as $\Delta$ glucose. Blood and urine samples for laboratory measurements were collected at overnight fast. Height and body weight $(\mathrm{BW})$ were measured, and body mass index (BMI) was calculated by dividing BW $(\mathrm{kg})$ by height squared $\left(\mathrm{m}^{2}\right)$. Plasma glucose levels were measured by automatic analyzer (GA09, A\&T, Fujisawa, Japan) using glucose oxidase method. HbA1c levels were measured by the automatic analyzer (HLC-723G8, TOSOH Bioscience, Tokyo, Japan) using high performance liquid chromatography (HPLC) method. Both plasma insulin concentrations as immunoreactive insulin (IRI) and serum CPR were measured using an electrochemiluminescence method (cobas 6000, Roche Diagnostics Japan, Tokyo, Japan). Other biochemical values were measured by the automatic analyzer (LABOSPECT 008, HITACHI High-Technologies, Tokyo, Japan).

We assessed correlations between $\Delta$ glucose and clinical parameters including BMI, duration of diabetes, HbA1c, serum CPR during GST, urinary CPR, serum lipids, serum FFA, liver function, the indices of residual liver function, renal function, and urinary albumin excretion (UAE). As renal function, we employed serum creatinine, cystatin $\mathrm{C}$ and eGFR. We calculated eGFR using the previously established equation for eGFR in Japanese subjects, which was calculated from serum creatinine, gender, and age in individual subjects [10].

\section{Statistical analysis}

Data are expressed as mean \pm SEM. The correlation coefficient was determined using Pearson's correlation coefficient. We performed a multiple linear regression analysis to evaluate clinical parameters independently showing significant correlations with eGFR 1 year later among 119 participants whom we could continuously follow up after the discharge. Data were analyzed using GraphPad Prism 5 (GraphPad Software Inc., San Diego, CA, USA) and Ekuseru-Toukei 2015 (Social Survey Research Information Co., Ltd., Tokyo, Japan). A p-value $<0.05$ was considered statistically significant.

\section{Results}

\section{Clinical characteristics and parameters}

The clinical characteristics and parameters of the total 209 participants are shown in Table 1 . The mean age was $60.7 \pm 1.0$ years, mean BMI was $27.5 \pm 0.4 \mathrm{~kg} / \mathrm{m}^{2}$, mean diabetic duration was $13.0 \pm 0.8$ years, and mean HbA1c level was $9.7 \pm 0.1 \%$ at the time of administration. For the GST, the mean plasma glucose at fasting and $6 \mathrm{~min}$ after glucagon injection were $122.2 \pm 1.6$ and $140.4 \pm 1.6 \mathrm{mg} / \mathrm{dl}$, respectively, and the mean $\Delta$ glucose was $18.2 \pm 0.5 \mathrm{mg} / \mathrm{dl}$. Additionally, there was no significant difference in $\Delta$ glucose among subjects with treated by glucose lowering agents, especially with or without biguanides or dipeptidyl peptidase-4 (DPP-4) inhibitors, which may influence the value of $\Delta$ glucose (data not shown).

\section{Correlations between $\Delta$ glucose and clinical parameters}

First, we examined the correlations between $\Delta$ glucose and clinical parameters as follows: age, BMI, duration of diabetes, HbA1c, serum CPR during GST, daily urinary $\mathrm{CPR}$, serum lipids, FFA, liver function and residual liver function, renal function, and UAE (Table 2). We observed positive correlation between $\Delta$ glucose and FFA $(r=$ 0.2117, $p=0.0025$; Fig. 1a), which is known to stimulate gluconeogenesis. Interestingly, $\Delta$ glucose showed positive correlation with eGFR at baseline $(r=0.2108, p=0.0025$; Fig. 1b), and inverse correlation with serum creatinine $(r=-0.2166, p=0.0017)$ and cystatin $C(r=-0.1515, p=$ $0.0302)$. On the other hand, we observed no relationship between $\Delta$ glucose and liver function such as AST and ALT, and the indices of residual liver function such as serum albumin, ChE, bilirubin, PT, total cholesterol, triglyceride, HDL cholesterol, and LDL cholesterol.

\section{Determinants for the future renal function in multiple regression analysis}

Since we observed that $\Delta$ glucose correlated with present renal function, we hypothesized that $\Delta$ glucose is also related to the future renal function and could be a determinant of the future renal function. Then, we further performed multiple regression analysis to identify the variables associated with eGFR after 1 year. We observed positive relationship between $\Delta$ glucose and eGFR 1 year later $(r=0.2412, p=0.0082$; Fig. $1 \mathrm{c})$ similarly to eGFR at baseline. Intriguingly, multiple regression analysis revealed that BMI $(\beta=0.1830, p=0.0337), \mathrm{HbA1c}$ $(\beta=0.2909, p=0.0008)$, total cholesterol $(\beta=-1.4550$, $p=0.0119)$, HDL-cholesterol $(\beta=0.5937, p=0.0053)$, LDL-cholesterol $(\beta=1.3343, p=0.0073)$, UAE $(\beta=-$ 0.3141, $p=0.0040)$, and $\Delta$ glucose $(\beta=0.2308, p=0.0034)$ were independent determinants of the eGFR after 1 year (Table 3).

\section{Discussion}

The clinical significance of $\Delta$ glucose as the increment of plasma glucose levels during GST has not yet been elucidated, although it is assumed mostly to reflect a part of HGO by glucagon. To the best of our knowledge, this is the first study to investigate the relationship between $\Delta$ glucose during GST and various clinical parameters in subjects with T2DM.

First, we demonstrated that $\Delta$ glucose was positively associated with FFA. FFA is known to increase HGO via stimulation of gluconeogenesis in the liver. The mechanisms how FFA stimulates gluconeogenesis can be attributed to the generation of 1) acetyl-CoA derived from FFA oxidation, which activates pyruvate carboxylase, 2) 
Table 1 Clinical characteristics and parameters

\begin{tabular}{|c|c|c|c|}
\hline \multirow{3}{*}{$\begin{array}{l}\text { Gender (male/female) } \\
\text { Age (years) }\end{array}$} & \multicolumn{3}{|c|}{$n=209$} \\
\hline & $108 /$ & & \\
\hline & 60.7 & \pm & 1.0 \\
\hline $\mathrm{BMI}\left(\mathrm{kg} / \mathrm{m}^{2}\right)$ & 27.5 & \pm & 0.4 \\
\hline Systolic blood pressure $(\mathrm{mmHg})$ & 116.6 & \pm & 0.9 \\
\hline Diastolic blood pressure (mmHg) & 67.6 & \pm & 0.7 \\
\hline Diabetic duration (years) & 13.0 & \pm & 0.8 \\
\hline $\mathrm{HbA1c}(\%)$ & 9.7 & \pm & 0.1 \\
\hline Glucose at $0 \mathrm{~min}(\mathrm{mg} / \mathrm{dl})$ & 122.2 & \pm & 1.6 \\
\hline Glucose at $6 \mathrm{~min}(\mathrm{mg} / \mathrm{dl})$ & 140.4 & \pm & 1.6 \\
\hline$\Delta$ Glucose $(\mathrm{mg} / \mathrm{dl})$ & 18.2 & \pm & 0.5 \\
\hline Serum CPR at 0 min $(\mathrm{ng} / \mathrm{ml})$ & 1.84 & \pm & 0.08 \\
\hline Serum CPR at 6 min $(n g / m l)$ & 3.56 & \pm & 0.14 \\
\hline$\triangle \mathrm{CPR}(\mathrm{ng} / \mathrm{ml})$ & 1.72 & \pm & 0.07 \\
\hline AST (IU/I) & 31.6 & \pm & 1.8 \\
\hline $\mathrm{ALT}(\mathrm{IU} / \mathrm{I})$ & 35.9 & \pm & 2.6 \\
\hline Albumin $(\mathrm{g} / \mathrm{dl})$ & 3.97 & \pm & 0.03 \\
\hline Cholinesterase (IU/I) & 340.4 & \pm & 5.5 \\
\hline Total Bilirubin (mg/dl) & 0.80 & \pm & 0.02 \\
\hline PT-INR & 0.99 & \pm & 0.01 \\
\hline Total Cholesterol (mg/dl) & 186.5 & \pm & 2.7 \\
\hline Triglyceride (mg/dl) & 146.1 & \pm & 6.3 \\
\hline HDL-Cholesterol (mg/dl) & 44.1 & \pm & 0.9 \\
\hline LDL-Cholesterol (mg/dl) & 116.7 & \pm & 2.3 \\
\hline Apolipoprotein $\mathrm{A}^{-1}(\mathrm{mg} / \mathrm{dl})$ & 124.1 & \pm & 1.5 \\
\hline Apolipoprotein B (mg/dl) & 95.9 & \pm & 1.5 \\
\hline Apolipoprotein E (mg/dl) & 4.5 & \pm & 0.1 \\
\hline Lipoprotein (a) (mg/dl) & 20.7 & \pm & 1.7 \\
\hline Free Fatty Acid (mEq/l) & 0.56 & \pm & 0.02 \\
\hline Remnant Like Particle Cholesterol (mg/dl) & 5.37 & \pm & 0.35 \\
\hline Serum Creatinine (mg/dl) & 0.76 & \pm & 0.02 \\
\hline Estimated GFR (ml/min/1.73m²) & 82.4 & \pm & 2.3 \\
\hline$\geqq 30$ and $<45, \mathrm{n}(\%)$ & & 24 & $(11.5)$ \\
\hline$\geqq 45$ and $<60, \mathrm{n}(\%)$ & & 23 & $(11.0)$ \\
\hline$\geqq 60$ and $<90, \mathrm{n}(\%)$ & & 86 & $(41.1)$ \\
\hline$\geqq 90, \mathrm{n}(\%)$ & & 76 & $(36.4)$ \\
\hline Serum Cystatin C (mg/dl) & 0.90 & \pm & 0.02 \\
\hline Urinary Albumin (mg/gCr) & 257.6 & \pm & 55.7 \\
\hline Urinary Albumin (mg/day) & 256.0 & \pm & 50.0 \\
\hline
\end{tabular}

Treatment

$\begin{array}{lll}\text { Glucose lowering agents } & & \\ \text { Insulin, } \mathrm{n}(\%) & 162 & (77.5) \\ \text { Biguanides, } \mathrm{n}(\%) & 59 & (28.2) \\ \text { Sulfonylureas, n (\%) } & 27 & (12.9) \\ \text { DPP-4 inhibitors, n (\%) } & 118 & (56.4)\end{array}$

Table 1 Clinical characteristics and parameters (Continued)

\begin{tabular}{|c|c|c|}
\hline$n=209$ & & \\
\hline GLP-1 R agonists, $\mathrm{n}(\%)$ & 17 & $(8.1)$ \\
\hline Others, n (\%) & 43 & $(20.6)$ \\
\hline Hypertension, n (\%) & 109 & $(52.2)$ \\
\hline \multicolumn{3}{|l|}{ Antihypertensive agents in subjects with hypertension } \\
\hline Angiotensin-converting enzyme inhibitors, n (\%) & 7 & $(6.4)$ \\
\hline Angiotensin receptor blockers, $\mathrm{n}(\%)$ & 79 & $(72.5)$ \\
\hline Calcium channel blockers, n (\%) & 72 & $(66.1)$ \\
\hline Diuretics, n (\%) & 33 & $(30.3)$ \\
\hline Alpha-blockers, n (\%) & 10 & $(9.2)$ \\
\hline Beta-blockers, n (\%) & 5 & $(4.6)$ \\
\hline
\end{tabular}

The data are presented as means \pm SEM. BMI Body mass index, CPR C-peptide immunoreactivity, AST Aspartate aminotransferase, ALT Alanine

aminotransferase, $P T$-INR Prothrombin time-international normalized ratio, $\mathrm{HDL}$ High-density lipoprotein, $L D L$ Low-density lipoprotein, GFR Glomerular filtration rate, DPP-4 Dipeptidyl peptidase-4, GLP-1 Glucagon-like peptide-1

nicotinamide adenine dinucleotide $(\mathrm{NADH})$, which is used for the formation of glyceraldehyde 3-phosphate from 1,3-bisphosphoglycerate, and 3) adenosine triphosphate (ATP), which is used as an energy source [11]. Chen and colleague showed that increment of plasma FFA levels results in increased gluconeogenesis, and FFA positively correlates to gluconeogenesis in humans [12]. Based on these previous findings, the positive relationship between $\Delta$ glucose by exogenous glucagon and FFA in this study is assumed to reflect the increment of blood glucose levels by FFA-associated gluconeogenesis in the liver.

Second, we anticipated that $\Delta$ glucose was associated with both liver function or the indices of residual liver function, since the liver is the most important organ supplying glucose into the circulation in the body and $\Delta$ glucose is presumably to reflect a part of HGO [1]. However, we observed no relationship between $\Delta$ glucose and liver function such as AST and ALT, or the indices of residual liver function such as serum albumin, ChE, bilirubin, PT, and cholesterol. Why was $\Delta$ glucose not associated with both liver function or the indices of residual liver function? Indeed, AST and ALT are established as the clinical indices of liver function, but these parameters are valuable only when serum levels are elevated at the liver injury or inflammation. In other words, we presume that both AST and ALT might not be perfect indicators which directly reflect the functional capacity of the liver. Additionally, the liver function of the participants in the current study was almost within normal range and was in a relatively narrow range with small variation. These results are also considered to be the reasons why AST and ALT were not related to $\Delta$ glucose in the current study. 
Table 2 Correlation between $\Delta$ glucose and clinical parameters

\begin{tabular}{|c|c|c|c|}
\hline Variables & & $r$ & $p$ value \\
\hline Age (years) & - & 0.0631 & 0.3641 \\
\hline BMI $\left(\mathrm{kg} / \mathrm{m}^{2}\right)$ & & 0.0261 & 0.7071 \\
\hline Diabetic duration (years) & - & 0.1238 & 0.0741 \\
\hline HbA1c (\%) & - & 0.1165 & 0.0929 \\
\hline Serum CPR at $0 \mathrm{~min}(\mathrm{ng} / \mathrm{ml})$ & - & 0.1069 & 0.1235 \\
\hline Serum CPR at 6 min $(\mathrm{ng} / \mathrm{ml})$ & - & 0.0352 & 0.6124 \\
\hline$\Delta C P R(n g / m l)$ & & 0.0572 & 0.4108 \\
\hline Urinary CPR ( $\mu \mathrm{g} /$ day) & - & 0.0282 & 0.6875 \\
\hline AST (IU/I) & - & 0.0659 & 0.343 \\
\hline ALT (IU/I) & - & 0.0777 & 0.2634 \\
\hline Albumin (g/dl) & & 0.0073 & 0.9162 \\
\hline Cholinesterase (IU/I) & & 0.0332 & 0.6354 \\
\hline Total Bilirubin (mg/dl) & & 0.0555 & 0.4252 \\
\hline PT-INR & - & 0.1315 & 0.0602 \\
\hline Total Cholesterol (mg/dl) & - & 0.0087 & 0.9007 \\
\hline Triglyceride (mg/dl) & & 0.1092 & 0.1155 \\
\hline HDL-Cholesterol (mg/dl) & & 0.0215 & 0.7569 \\
\hline LDL-Cholesterol (mg/dl) & - & 0.0523 & 0.4518 \\
\hline Apolipoprotein $\mathrm{A}^{-1}$ (mg/dl) & & 0.1029 & 0.145 \\
\hline Apolipoprotein B (mg/dl) & & 0.03093 & 0.6621 \\
\hline Apolipoprotein E (mg/dl) & & 0.03105 & 0.6609 \\
\hline Lipoprotein (a) (mg/dl) & & 0.03749 & 0.5972 \\
\hline Free Fatty Acid (mg/dl) & & 0.2117 & 0.0025 \\
\hline Remnant Like Particle Cholesterol (mg/dl) & & 0.1065 & 0.1322 \\
\hline Serum Creatinine (mg/dl) & - & 0.2166 & 0.0017 \\
\hline Estimated GFR (ml/min/1.73m²) & & 0.2108 & 0.0025 \\
\hline Serum Cystatin C (mg/dl) & - & 0.1515 & 0.0302 \\
\hline Urinary Albumin (mg/gCr) & & 0.005094 & 0.9418 \\
\hline Urinary Albumin (mg/day) & - & 0.01433 & 0.838 \\
\hline
\end{tabular}

Pearson's correlation coeficients between $\Delta$ glucose and clinical parameters

How about serum albumin, ChE, bilirubin, PT, and cholesterols? These parameters, reflecting the synthetic (albumin, ChE, prothrombin, and cholesterols) or elimination (bilirubin) functions of the liver [13], have been well entrenched in assessment of residual liver function. In particular, albumin, bilirubin, and PT constitute 'ChildPugh score,' the indicator of both residual liver function and prognosis in the subjects with liver cirrhosis [13]. Although we speculate these parameters are associated with $\Delta$ glucose during GST presumably reflecting HGO by glucagon, we failed to observe any relationship between them. Thus, we consider several possible reasons for our results. First, in the current study, we excluded the subjects with liver dysfunction or liver cirrhosis, who might be with impaired parameters such as albumin, bilirubin and PT. That is, similarly to AST and ALT, it can be mentioned that these parameters were also within a normal and a narrow range. Second, these parameters are influenced by various factors other than the synthetic and elimination functions in the liver. For instance, serum albumin levels are generally altered in the presence of proteinuria, hypermetabolism, and malnutrition. Additionally, serum bilirubin levels are also influenced by the existence of renal insufficiency and hemolysis [13]. We consider these variables are the indices not independently reflecting the residual liver function simply represented by synthetic and elimination functions in the liver, thus the results were away from our speculations.

Interestingly, we observed that $\Delta$ glucose showed positive relationship with eGFR, and inverse relationship with serum creatinine and cystatin $\mathrm{C}$. The kidney also plays critical roles in glucose metabolism via gluconeogenesis, glucose utilization, and glucose reabsorption. Renal glucose production is only through gluconeogenesis, since the kidney cannot produce glucose via glycogenolysis because the kidney has much smaller amount of glycogen than the liver and renal cells can synthesize glycogen but lack glucose-6-phosphatase [14]. Indeed, liver and kidney are almost equivalently involved in glucose production via gluconeogenesis in the post-absorptive state of normal subjects [4, 14]. Moreover, patients with T2DM exhibit abnormal increase of glucose release into the circulation through gluconeogenesis in both liver and kidney [5]. Thus, renal gluconeogenesis not only plays an important role in maintaining homeostasis, but also is involved in pathogenesis of T2DM. These previous findings and our observation provide us the speculation that $\Delta$ glucose might reflect the capacity for glucose release via renal gluconeogenesis in T2DM.

However, the liver, but not the kidney, has been considered to be the main organ of gluconeogenesis regulated by glucagon. Previous study using isolated perfused rat kidney showed that glucagon does not stimulate gluconeogenesis in the kidney [15]. Furthermore, glucagon stimulates gluconeogenesis from glutamine and increases glucose output not in the kidney but in the liver in human [16]. On the other hand, a recent report revealed that both kidney and intestine induce gluconeogenesis by glucagon in a mouse model for liver-specific deletion of glucose production, concluding that current dogma concerning the roles of the liver and the extrahepatic gluconeogenic organs in glucose homeostasis needs to be revisited [17]. Therefore, we speculate that these observations might explain why glucagon-derived glucose increment was related to renal function in our current study.

Based on our results, we further hypothesized that $\Delta$ glucose could be the determinant of the future renal function. Then, we performed multiple regression analysis to clarify the variables associated with eGFR after a year. Multiple regression analysis revealed that $\Delta$ glucose 
A

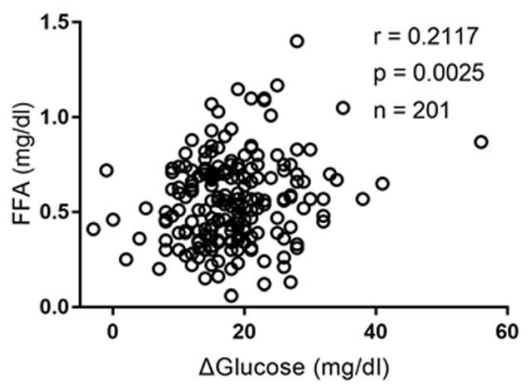

C

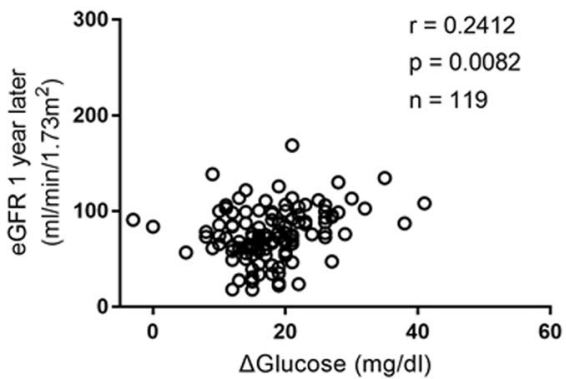

B

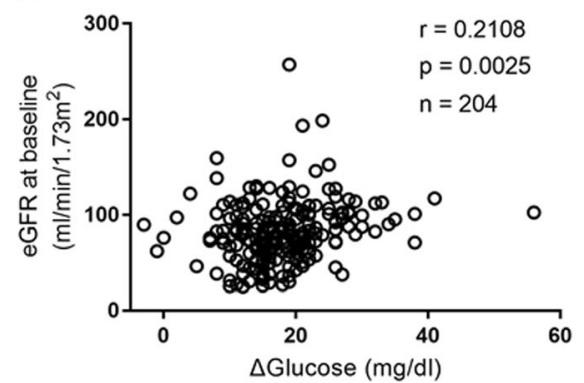

Fig. 1 Correlation between $\Delta$ glucose and FFA, eGFR at baseline, and eGFR 1 year later. Pearson's correlation coefficients between $\Delta$ glucose and free fatty acids (a), eGFR at baseline $(\mathbf{b})$, and eGFR one year later $(\mathbf{c})$

was an independent determinant for the eGFR after 1 year, in addition to BMI, HbA1c, serum lipids, and UAE. Previous several studies already showed that obesity, glycemic control, serum lipids, and proteinuria were respectively the predictors for the development of chronic

Table 3 Determinants of eGFR one year later in multiple linear regression analysis

\begin{tabular}{|c|c|c|c|}
\hline Factors & & $\beta$ & $p$ value \\
\hline BMI & & 0.1830 & 0.0337 \\
\hline Diabetic duration & - & 0.0377 & 0.6462 \\
\hline $\mathrm{HbA1c}$ & & 0.2909 & 0.0008 \\
\hline Systolic blood pressure & - & 0.0272 & 0.7669 \\
\hline Diastolic blood pressure & & 0.0459 & 0.6151 \\
\hline$\Delta$ Glucose & & 0.2308 & 0.0034 \\
\hline$\triangle C P R$ & & 0.1048 & 0.2296 \\
\hline AST & - & 0.0280 & 0.8451 \\
\hline ALT & & 0.0171 & 0.9080 \\
\hline Albumin & - & 0.0597 & 0.5522 \\
\hline Total Cholesterol & - & 1.4550 & 0.0119 \\
\hline Triglyceride & & 0.1628 & 0.3667 \\
\hline HDL-Cholesterol & & 0.5937 & 0.0053 \\
\hline LDL-Cholesterol & & 1.3343 & 0.0073 \\
\hline Free Fatty Acid & & 0.0889 & 0.2808 \\
\hline Urinary Albumin (mg/day) & - & 0.3141 & 0.0040 \\
\hline
\end{tabular}

Multiple regression analysis. Response variable, eGFR one year later kidney disease $[18,19]$. Our results are very interesting since it suggests that $\Delta$ glucose is not only related to the present renal function but also a determinant for the future renal function in addition to other metabolic parameters which has been already examined. The correlation between $\Delta$ glucose and renal function could be linked to the view that $\Delta$ glucose is a proxy of the functional activity of the nephrons.

There are several limitations in this study. First, our current study was conducted with retrospective crosssectional design. Second, our results were based on the relatively small population without common selection criteria at single hospital. Third, the subjects of the current study exhibited higher HbA1c levels among diabetic patients. Although we performed GST after adequate glycemic control, we need further investigation in populations with better glycemic control. Fourth, we did not investigate mechanistic analysis that can explain our results in this study, especially in the relationship between $\Delta$ glucose and renal function. Prospective multicenter cohort studies with sufficient number of participants are necessary to clarify the relationship between $\Delta$ glucose and various clinical parameters especially in renal functions for further understanding.

\section{Conclusions}

In summary, this is the first report to show the clinical implication of $\Delta$ glucose during GST. We observed the relationship between $\Delta$ glucose and FFA. Furthermore, 
we revealed the relationship between $\Delta$ glucose and both present and future renal function. Our present study suggests that $\Delta$ glucose might be related to gluconeogenesis in the kidney, and we believe that $\Delta$ glucose could be the determinant of future renal function in type 2 diabetes.

\section{Abbreviations}

ALT: Alanine aminotransferase; AST: Aspartate aminotransferase; BMI: Body mass index; BW: Body weight; ChE: Cholinesterase; CPR: C-peptide immunoreactivity; DPP-4: Dipeptidyl peptidase-4; eGFR: Estimated glomerular filtration rate; FFA: Free fatty acids; GST: Glucagon stimulation test: HDL: High-density lipoprotein; HGO: Hepatic glucose output; HPLC: High performance liquid chromatography; IRI: Immunoreactive insulin; LDL: Lowdensity lipoprotein; PT: Prothrombin time; T2DM: Type 2 diabetes mellitus; UAE: Urinary albumin excretion

\section{Acknowledgements}

Not applicable.

\section{Authors' contributions}

YTake, YF, RB, MS, TA, TY, HS, AA, YTaki, TO and MH contributed to the study concept and design; YTake, YF acquired data; YTake, YF, RB, MS, TA, TY, HS, $\mathrm{AA}, \mathrm{YT}$ aki, $\mathrm{TO}$ and $\mathrm{MH}$ analyzed and interpreted the data and performed statistical analysis; YTake and YF drafted the manuscript; YTake, YF, RB, MS, TA, TY, HS, AA, YTaki, TO and MH reviewed the manuscript for important intellectual content; All authors have read and approved the manuscript.

\section{Funding}

No funding was obtained for this study.

\section{Availability of data and materials}

The datasets used and/or analyzed during the current study are available from the corresponding author on reasonable request.

\section{Ethics approval and consent to participate}

The study was approved by the ethical board of Asahikawa Medical University, Asahikawa, Japan (Approval number: 17104) and performed in accordance with the declaration of Helsinki. Participants were informed through an opt-out consent form which stated that previously obtained medical information would be used in this retrospective study on the Asahikawa Medical University Research Ethics Committee's web site.

\section{Consent for publication}

Not applicable.

\section{Competing interests}

The authors declare that they have no competing interests.

Received: 16 July 2019 Accepted: 16 September 2019

Published online: 15 October 2019

\section{References}

1. Gromada J, Franklin I, Wollheim CB. Alpha-cells of the endocrine pancreas: 35 years of research but the enigma remains. Endocr Rev. 2007;28:708-23.

2. Scheen AJ, Castillo MJ, Lefebvre PJ. Assessment of residual insulin secretion in diabetic patients using the intravenous glucagon stimulatory test: methodological aspects and clinical applications. Diabetes Metab. 1996;22: 397-406.

3. Vaque $P$, Nguyen $L$. Rationale and methods for the estimation of insulin secretion in a given patient: from research to clinical practice. Diabetes. 2002:51(Suppl 1):240-4

4. Gerich JE. Role of the kidney in normal glucose homeostasis and in the hyperglycaemia of diabetes mellitus: therapeutic implications. Diabet Med. 2010;27:136-42.

5. Meyer C, Stumvoll M, Nadkarni V, Dostou J, Mitrakou A, Gerich J. Abnormal renal and hepatic glucose metabolism in type 2 diabetes mellitus. J Clin Invest. 1998;102:619-24.

6. Frizzell M, Larsen PR, Field JB. Spontaneous hypoglycemia associated with chronic renal failure. Diabetes. 1973;22:493-8.
7. Garber AJ, Bier DM, Cryer PE, Pagliara AS. Hypoglycemia in compensated chronic renal insufficiency. Substrate limitation of gluconeogenesis. Diabetes. 1974;23:982-6.

8. Changani KK, Jalan R, Cox IJ, et al. Evidence for altered hepatic gluconeogenesis in patients with cirrhosis using in vivo 31-phosphorus magnetic resonance spectroscopy. Gut. 2001;49:557-64.

9. Joseph SE, Heaton N, Potter D, Pernet A, Umpleby MA, Amiel SA. Renal glucose production compensates for the liver during the anhepatic phase of liver transplantation. Diabetes. 2000:49:450-6.

10. Matsuo S, Imai E, Horio M, et al. Revised equations for estimated GFR from serum creatinine in Japan. Am J Kidney Dis. 2009:53:982-92.

11. Lam TK, Carpentier A, Lewis GF, van de Werve G, Fantus IG, Giacca A. Mechanisms of the free fatty acid-induced increase in hepatic glucose production. Am J Physiol Endocrinol Metab. 2003;284:E863-73.

12. Chen X, Iqbal N, Boden $\mathrm{G}$. The effects of free fatty acids on gluconeogenesis and glycogenolysis in normal subjects. J Clin Invest. 1993; 103:365-72.

13. Durand F, Valla D. Assessment of the prognosis of cirrhosis: child-Pugh versus MELD. J Hepatol. 2005;42:S100-7.

14. Alsahli M, Gerich JE. Renal glucose metabolism in normal physiological conditions and in diabetes. Diabetes Res Clin Pract. 2017;133:1-9.

15. Bowman RH. Gluconeogenesis in the isolated perfused rat kidney. J Biol Chem. 1970;245:1604-12.

16. Stumvoll M, Meyer C, Kreider M, Perriello G, Gerich J. Effects of glucagon on renal and hepatic glutamine gluconeogenesis in normal postabsorptive humans. Metabolism. 1998:47:1227-32.

17. Mutel E, Gautier-Stein A, Abdul-Wahed A, et al. Control of blood glucose in the absence of hepatic glucose production during prolonged fasting in mice: induction of renal and intestinal gluconeogenesis by glucagon. Diabetes. 2011;60:3121-31.

18. Iseki K, Ikemiya Y, Iseki C, Takishita S. Proteinuria and the risk of developing end-stage renal disease. Kidney Int. 2003;63:1468-74.

19. Yamagata K, Ishida K, Sairenchi T, et al. Risk factors for chronic kidney disease in a community-based population: a 10-year follow-up study. Kidney Int. 2007;71:159-66.

\section{Publisher's Note}

Springer Nature remains neutral with regard to jurisdictional claims in published maps and institutional affiliations.

\section{Ready to submit your research? Choose BMC and benefit from:}

- fast, convenient online submission

- thorough peer review by experienced researchers in your field

- rapid publication on acceptance

- support for research data, including large and complex data types

- gold Open Access which fosters wider collaboration and increased citations

- maximum visibility for your research: over $100 \mathrm{M}$ website views per year

At $\mathrm{BMC}$, research is always in progress.

Learn more biomedcentral.com/submissions 